\section{Estado, mujer y hogar en Chile. El rol disciplinario en publicaciones de época}

\section{State, women, and home in Chile. The disciplinary role in official period publications}

\author{
Francisca Pérez
}

\section{Resumen}

Los discursos que circulan alrededor de la mujer, la vida doméstica y el hogar en publicaciones oficiales y semanarios femeninos de época en

\footnotetext{
Universidad Academia de Humanismo Cristiano fperez@academia. cl. Este artículo se realizó en el marco del proyecto Fondecyt Posdoctorado 3130670 "Imaginarios de la mujer y la vida doméstica en chile 1920-1960". Una versión preliminar de este artículo fue presentada en el Seminario el Estado y lo domestico organizado por el Instituto de Humanidades de la Universidad Academia de Humanismo Cristiano y Flacso Ecuador el 4 de Septiembre del 2014 en la Universidad Academia de Humanismo Cristiano.
}

Chile durante la primera mitad del siglo XX se enmarcan en un conjunto de acciones ligadas con el disciplinamiento biopolítico entendido como la gestión estatal en relación con el gobierno de la sociedad. Dicha gestión se encarna en instituciones encargadas de divulgar e implementar políticas sociales relacionadas con la regulación de la vida familiar, ligadas directa o indirectamente con el Estado. En esta línea, el artículo se centra en el análisis de dos publicaciones oficiales que circularon durante la primera mitad del siglo XX; por un lado, la revista Comuna y Hogar publicada por el órgano de Municipalidades entre 1927-1959 y por otro la revista Servicio Social, que nace al alero Escuela de Trabajo Social de la Junta Nacional de Beneficencia en 1927. Se sostiene que, a partir del análisis de estas publicaciones, es posible avanzar en la comprensión del modo como el discurso estatal sobre la vida doméstica en el periodo se encarna en un conjunto de imaginarios sociales vinculados con el rol de la mujer en la sociedad, así como de las tensiones entre dichos imaginarios, las prácticas sociales y las políticas estatales del momento.

Palabras clave: hogar, domesticidad, mujer, biopolítica, prácticas policiales, discurso estatal

\begin{abstract}
Discourses surrounding women, domestic life and home in Chile in the first half of the 20th Century are framed in a series of actions related to the State's decisions related with a biopolitical disciplining understood as how society should be ruled. These decisions take the form of institutions, directly or indirectly connected to the State, which are in charge
\end{abstract}


of instituting or disseminating social policies. It is in this spirit that this paper focus in the discourses that circulated in official publications aligned with State decision-making in the first half of the $20^{\text {th }}$ Century. More specifically, it analyzes discourses that are directly related to the regulation of family life, with a particular emphasis on those that are targeted at women and domestic life in two periodic publications. One of them, "Comuna y Hogar" is published by the league of municipalities from 1927 to 1959 and the other "Servicio Social", is created by the first School of Social Work of the Junta Nacional de Beneficencia (Chile's Welfare Administration) in 1927. This paper argues that these two publications allow for a greater comprehension of the State discourse around domestic life and women in the period.

Key words: home, domesticity, women, biopolitics, police practices, State discourse

\section{Introducción}

La construcción de los imaginarios sociales relacionados con la mujer, la vida doméstica y el hogar en el contexto chileno entre 1920 y 1960 constituye el tema central de este artículo. Se propone comprender el modo en que dichos imaginarios contribuyeron en la consolidación de un modelo doméstico centrado en la figura femenina, considerando las tensiones entre los elementos modernizadores y conservadores propios de un periodo caracterizado por importantes transformaciones sociales relativas a la regulación de la vida doméstica. En este escenario, destacan las reformas sociales impulsadas durante los gobiernos del Frente Popular durante la primera mitad del siglo $\mathrm{XX}$, las que destacan la centralidad de la familia en tanto eje estructurante del proyecto modernizador del Estado. En esta línea bajo el gobierno de Pedro Aguirre Cerda, se instauran un conjunto de disposiciones destinadas a la consolidación del rol femenino como dueña de casa y el masculino de proveedor: Estas reformas impactarán fuertemente en la configuración de la vida familiar y doméstica de los sectores populares y medios tal como ha sido destacado por otras investigaciones (Rosemblatt, 1995).

Desde esta perspectiva, se analizará la Revista de Servicio Social, publicación que surge junto con la disciplina, en el año 1927, y que encarna la mirada institucional sobre el ámbito de la vida doméstica a través del rol desempeñado por las trabajadoras sociales en la consolidación de la imagen femenina y su relación preponderante en la vida hogareña. Parte de este discurso quedó plasmado en la labor desempeñada por las entonces visitadoras sociales, la que ha sido ampliamente estudiada para el caso chileno (Illanes 2007; Valdés, Caro y Peña, 2001; Rosemblatt 1995). Desde la década del 20 las visitadoras sociales tendrán un rol gravitante en lo que concierne a las políticas sociales corporales del Estado, en referencia con aquellas políticas insertas en un marco modernizador liderado por los principios del higienismo y una nueva concepción de la salud de la época, principios que apelan al mejoramiento de las desfavorables condiciones de vida que experimentaban los sectores marginales de la sociedad. Sin embargo, este marco modernizador opera desde una lógica conservadora en lo que respecta a la división sexual del trabajo, tendiendo a naturalizar la posición de la mujer en el hogar y su rol en las actividades vinculadas con la esfera doméstica en general (Illanes 2007). 
En este escenario, para las visitadoras sociales las mujeres constituirán su principal foco de atención, en tanto encarnan el llamado a liderar el proceso de disciplinamiento de la familia, su campo de acción estaría dado por todo lo que se refiere a la producción, organización y mantención del hogar, tanto desde el punto de vista de las prácticas cotidianas vinculadas con las labores de cuidado, aseo y ornato, como desde el ámbito ético moral (Illanes 2007; Valdés, Caro y Peña; 2001). En este sentido, salud y moral configuran un binomio inseparable, que actúa dialécticamente como mecanismo de control biopolítico de los sujetos y sus cuerpos desde la esfera cotidiana del hogar. Disciplinamiento que se despliega desde un conjunto de técnicas en el contexto de la vida familiar del hogar (Foucault, 1998 y 2008). Tal como señala Jaques Donzelot, la familia -y en particular la familia francesa del siglo XVIII será modelada por un conjunto de estrategias de disciplinamiento y control lideradas por la medicina y el higienismo, ambas disciplinas desempeñarán un relevante papel en el adiestramiento moral de la familia desde el punto de vista del Estado. Más específicamente el autor señala la conexión sistemática de la moral con lo económico, para lo que es necesario un control detallado de la familia, una vigilancia continua de la vida privada de los pobres (Donzelot 1998).

En el caso chileno, el disciplinamiento de la familia es potenciado durante el periodo de los gobiernos del frente popular, a partir de un conjunto de acciones destinadas al control social y moral de sus miembros. Este rol fue desempeñado en parte por las visitadoras sociales, cuya labor es altamente valorada por las dueñas de casa, quienes las verán como aliadas en lo que se refiere a la organización moral de la vida doméstica (Rosemblatt 1995).

Por otra parte, el discurso institucional ligado con el disciplinamiento de la vida doméstica de este periodo se expresa en Comuna y Hogar $^{1}$, publicación inaugurada durante el gobierno de Ibáñez destinada a la divulgación de la labor de los municipios, en relación a sus competencias administrativas y legislativas, así como a la difusión del rol de las juntas de vecinos. Su principal interés estaba enfocado en la modernización de las municipalidades y la legitimación del papel de los alcaldes. En este contexto institucional de interés por lo público se abordan temáticas referidas a la urbanización y al urbanismo, incorporando el ámbito del hogar como uno de sus focos de interés. Se considera el hogar como un dispositivo fundamental en la activación del proceso de modernización municipal y del país. En este sentido, el ámbito doméstico se expresa en dos campos de acción; por un lado, se encarna en las ideas higienistas que desde principios del siglo XX tuvieron una presencia relevante en la concepción de la ciudad y la vida urbana y por otro lado en el rol de la mujer en el marco de la gestión municipal. Lo interesante es que el aporte femenino al municipio es restringido a la gestión de la mujer dentro del hogar. En esta perspectiva, a partir de esta publicación podremos aproximarnos a la mirada institucional respecto del rol público de la mujer, pero desde sus funciones domésticas (Perrot 2001).

A partir del análisis de ambas publicaciones el artículo apela a profundizar de manera específica la relación entre lo doméstico y lo femenino desde una perspectiva que permita

Esta publicación surge con el nombre de Comuna y Hogar entre los años 1929 y 1931, luego pasará a llamarse Boletín Municipal de la República entre 1932 y 1939 y, finalmente, Revista de las Municipalidades de la República en 1939 
dar cuenta de los procesos de naturalización largamente arraigados en la sociedad chilena, en donde la división sexual del trabajo ha trazado una vinculación ontológico-naturalizante entre la visión de la mujer como cuidadora - productora del hogar y el hombre como proveedor y sus respectivas vinculaciones a la esfera privada y pública (Pérez y Godoy 2009).

De este modo, cabe preguntarse ¿de qué manera el discurso institucional expresado en estas revistas deviene en la construcción de una mirada biopolítica de la vida doméstica? ¿de qué modo impactaron en la construcción de un modelo doméstico centrado en la mujer, en sectores populares y medios entre 1920 y 1960? ¿cómo se expresa la tensión entre el ímpetu modernizador del periodo con aquellos elementos de raigambre tradicional largamente asentados en la sociedad chilena desde el punto de vista de la relación entre la mujer y la vida doméstica? A modo de hipótesis señalamos que si bien este periodo se caracterizó por un proceso de modernización que se venía gestando desde comienzos del siglo XX, expresado en las transformaciones socioculturales y los cambios en los estilos de vida ligados a la paulatina tecnificación del hogar y la publicidad a ella asociada (Álvarez 2011) así como por la reconfiguración de las relaciones familiares expresadas en la reelaboración en la posición de hombres y mujeres frente a las esferas públicas y privadas, al mismo tiempo se refuerza un modelo tradicional de domesticidad centrado en la figura femenina.

En esta perspectiva, la sociedad chilena presenta formas ambiguas de vincular modernidad y tradición, lo que responde en parte, a las contradicciones de una naciente burguesía que transita entre los valores liberales propios de la modernidad y los de corte tradicional asociados con la elite, ambigüedad que se encarnará especialmente en la elaboración de una mirada conservadora tendiente a naturalizar el rol de la mujer en la vida doméstica y su vínculo con la esfera privada.

\section{Enfoque metodológico}

El enfoque metodológico de la investigación posdoctoral de la que se desprende este artículo se basó en la interpretación del discurso institucional y las representaciones sociales sobre la relación entre mujer y vida doméstica en los imaginarios sociales en las publicaciones seleccionadas. Desde el punto de vista epistemológico es posible encontrar un conjunto de representaciones y orientaciones de prácticas respecto del espacio doméstico y su cotidianidad plasmadas en este tipo de publicaciones de carácter institucionalnormativo, las que expresan simbólicamente los imaginarios sociales relacionados con la mujer y la vida doméstica del periodo.

En esta perspectiva, los medios escritos, dentro de los cuales destacan diarios y revistas históricamente han constituido uno de los principales canales de información en los cuales circulan y se reproducen los imaginarios sociales, lo que permite considerarlas como parte del imaginario social de la época, el que se configura por imágenes, textos $y$ diferentes tipos de relatos que encarnan ideas y representaciones de un colectivo sobre un tema en particular en un tiempo específico.

De este modo, el análisis considera los discursos en torno a la mujer y la vida doméstica del periodo como una fuente de valor documental susceptible de ser analizada desde una mirada 
interpretativa -deconstructiva otorgándole un status de construcción social y como expresión de imaginarios sociales que devienen prácticas y modos de hacer y que aportan en la consolidación del control biopolítico en torno a la familia y la vida doméstica.

Es decir, más que considerar dichos discursos como meras reproducciones de la domesticidad del periodo estudiado, se les otorga una capacidad performativa en la medida que constituyen una puesta en escena, sobre la vida doméstica. En ese sentido, constituyen, una interpretación interpretada (Geertz, 2003) que forma parte del imaginario social, por lo que permiten acceder a ideas y representaciones sociales acerca de la domesticidad del periodo. Entendiendo que la noción de imaginario no se restringe exclusivamente al estudio de las imágenes visuales, sino que incluye las ideas o elementos simbólicos, en palabras de Wunenburger, el imaginario sería en este sentido: "Un conjunto de producciones, mentales o materializadas en obras, a partir de imágenes visuales (cuadro, dibujo, fotografía) y lingüísticas (metáfora, símbolo, relato) que forman conjuntos coherentes y dinámicos que conciernen a una función simbólica en el sentido de una articulación de sentidos propios y figurados" (Wunenburger 2008).

A partir de lo anterior y reconociendo el rol que juega el plano psicológico individual en la construcción del imaginario, interesa a esta investigación remitirse al imaginario principalmente en dos sentidos: primero entendido como producto social y segundo en su capacidad activadora de ciertos comportamientos sociales. Haciendo referencia al primer punto, el imaginario social va más allá del plano teórico intelectual; tal como lo señala Charles Taylor (2004), éste corresponde a los modos en que las personas imaginan su existencia social, así como también a las formas de relacionarse socialmente, así como a sus expectativas sobre los diferentes ámbitos de su existencia social. El imaginario social está constituido por aquellas ideas que norman y delimitan esas expectativas expresándose en imágenes, leyendas e historias. Los imaginarios sociales además constituyen ideas compartidas por grupos de personas y se expresan en prácticas (Taylor 2004).

En este sentido, los imaginarios sociales y los discursos biopolíticos en torno a la vida doméstica se objetivan en las representaciones y prácticas que los producen y reproducen. En esta perspectiva, es posible evidenciar un conjunto de orientaciones de prácticas respecto de la vida doméstica y su cotidianidad plasmadas en publicaciones oficiales de época, en los que éstos se despliegan y materializan. Los medios escritos, dentro de los cuales destacan este tipo de publicaciones, históricamente han constituido uno de los principales canales de información en los cuales circulan y se reproducen estos imaginarios.

De este modo, este tipo de publicaciones producen una retórica respecto de la vida cotidiana, instalándose como un deber ser, como modelo social que potencia determinadas prácticas sociales, las que además son apropiadas por los sujetos a través de su lectura e interpretación particular.

\section{Discursos biopolíticos en la producción del hogar y el proyecto doméstico.}

La relación entre el Estado y vida doméstica ha sido tema de interés por los estudios 
de género desde diferentes perspectivas y miradas teóricas. Podemos señalar que parte de la discusión se inserta en el contexto del debate contemporáneo acerca de la compleja relación entre las dimensiones de lo público y privado, entendidas como esferas que organizan, estructuran y definen la vida social. Desde esta perspectiva destacan los trabajos y aportes realizados por la historiografía francesa representada notablemente en la Historia de la Vida Privada, obra dirigida por Philippe Aries y Georges Duby (2001), donde se aborda desde la relevancia de la vida privada discutiendo sus límites con la vida pública desde diferentes perspectivas. Por otra parte, los trabajos de Wendy Brown (1999) y Carol Pateman (2000) abordan de manera más específica el papel que ha jugado el Estado en la regulación de la vida privada desde una aproximación masculinizante.

En este marco, Pateman ha señalado que gran parte del debate del movimiento feminista ha girado en torno a la dicotomía público/ privado. Destacando especialmente el carácter patriarcal del Estado de Bienestar moderno, argumento que la autora desarrolla desde una crítica a la distinción entre la esfera privada familiar y la pública ligada al Estado y sus políticas sociales.

Pateman plantea que dicha dicotomía puede ser relativizada, en tanto que, si bien la esfera privada ha sido percibida como el lugar por excelencia de las mujeres, éstas no han estado excluidas totalmente del mundo público a través de las políticas del Estado de bienestar las que han ayudado a asegurar que "... la experiencia cotidiana de las mujeres conforme a la separación entre la existencia privada y pública" (Pateman 2000: 6). En efecto, la vida femenina ha sido de interés del Estado desde comienzos del siglo XX, en donde "... las políticas de bienestar han alcanzado desde lo público a lo privado, y han ayudado a sostener una estructura de vida familiar" (Pateman 2000: 6).

En esta perspectiva, la vida doméstica estaría en el centro de la sociedad civil, por lo que no se puede escindir de la esfera pública (Pateman 2000). Interesa, por tanto, ahondar en los mecanismos a través de los cuales el Estado chileno desde su acción discursiva, ha regulado el papel de la mujer en la sociedad desde una mirada tendiente a naturalizar una suerte de vínculo ontológico con la casa y la vida doméstica.

El Estado impacta sobre la vida privada familiar a través de políticas sociales que colonizan y administran el ámbito doméstico desde una visión masculina del poder, ingresando en el gobierno de la vida, desde la esfera cotidiana del hogar. En esta línea, como señala Brown el Estado logra influir en la privacidad de los sujetos con la finalidad de poder administrar su vida efectivamente (Brown 1999).

Las estrategias discursivas a partir de las cuales el Estado logra penetrar en la vida privada se expresan como mecanismos policiales que operan sobre la vida familiar (Foucault 1999; Donzelot 1998). El Estado, por tanto, requiere de estas formas de disciplinamiento a nivel discursivo, en tanto permiten potenciar acciones y políticas concretas. En esta lógica, indagar sobre los discursos desplegados en publicaciones de organismos relacionados con el quehacer estatal, que intervienen en la administración de la vida privada del hogar, permite ampliar la comprensión sobre los efectos del Estado en la vida doméstica y más ampliamente en el modo como dicha intervención adquiere un impacto en la dimensión biopolítica. 
Los argumentos de Deborah Poole y Veena Das en torno a la penetración del poder sobre lo que denominan como los márgenes del Estadoen relación con todo lo que queda fuera de la jurisdicción del ámbito público- complementan este enfoque (Das y Poole 2008). En esta línea, la vida doméstica aparentemente emergería como espacio marginal de la acción estatal, contexto en el cual se sitúa el análisis de los discursos normalizadores -moralizantes e higienistas del periodo en cuestión, respecto de la relación de la mujer con la vida doméstica, Las autoras señalan que la literatura reciente ocupada por el tema de poder del Estado ha trasladado el énfasis en lo jurisdiccional al de la "administración de la vida" de donde surgen acepciones como estado higiénico, inmunizador o terapéutico (Das y Poole 2008).

En esta misma línea, tal como señala Pedraza respecto al régimen biopolítico en América Latina existiría una relación entre educación disciplinaria del cuerpo individual, regulación de la población y formas modernas de gobierno (Pedraza 2004: 7).

Este constituye el sentido específico desde el cual interesa situar el concepto de biopolítica propuesto por Foucault, considerando su capacidad de control sobre la vida familiar y el hogar, -expresado explícitamente en un conjunto de estrategias discursivas desplegadas en secciones y artículos de estas publicaciones y que opera desde un aparataje ideológico que orienta formas de comportamiento de los cuerpos y las familias en el contexto íntimo del hogar. Como destaca Pedraza, en América Latina la modernidad se instaló desde el estado, a partir de una noción de orden entendida como una disposición confiable de jerarquías que regulan la distribución del tiempo y el uso del espacio (Pedraza 2004)
De este modo, el concepto de biopolítica, sugiere el anhelo racionalizador de las prácticas de control social disciplinario impuestas por los gobiernos y se entiende como la forma a partir la cual el estado ha intentado desde el siglo XVIII, tanto en Europa como en América Latina, controlar los problemas que afectan a la población, especialmente aquellos relativos con la salud, la higiene, la natalidad o la vejez entre otros.

En esta línea disciplinaria es pertinente incorporar los planteamientos desarrollados por Jaques Donzelot respecto de las prácticas policiales respecto de la familia y que se definen como aquellas acciones que desempeñan un papel central en la mantención de la cohesión social (Donzelot 1998). En este contexto, el trabajo social llevado a cabo por profesionales dedicados al asistencialismo actúa como agente civilizador del cuerpo social, desde el despliegue de estrategias técnicas tendientes a reemplazar la acción desarrollada previamente por la caridad (Donzelot 1998).

Existiría, como señala el autor, un tránsito paulatino desde la acción caritativa de la iglesia sobre los sectores populares, hacia la acción desplegada posteriormente por el Estado, encarnada en la labor desempeñada por Beneficencia Pública, tanto en el mundo europeo como en las repúblicas latinoamericanas de fines del siglo XIX. Este tránsito apela hacia un control social basado en principios racionalizadores de carácter técnico propios de la modernidad aplicados por los gobiernos liberales que cuestionarán el rol desempeñado por la iglesia y las elites aristocráticas en su relación con los sectores populares hacia fines del siglo XIX.

Surge así una reelaboración de cómo el Estado se vincula con los sectores populares sustentada 
en preceptos modernos que acompañan reformas higienistas de fines del XIX y principios del XX. Sin embargo, al mismo tiempo dicha relación se levanta desde valoraciones de corte tradicional, especialmente respecto del estatus de la familia y sus miembros.

Acorde a lo anterior como lo señala Donzelot en relación con la sociedad del Antiguo Régimen francés, la familia es sujeto y objeto de gobierno "Sujeto, por la distribución interna de sus poderes: la mujer, los niños y las personas asociadas (parientes, domésticos, aprendices) están sometidos al jefe de familia. Objeto, en el sentido de que el jefe de familia se sitúa también en relaciones de dependencia (...) la familia constituía, pues, un plexo de relaciones de dependencia indisociablemente privadas y públicas, una red de hilos sociales que organizan a los individuos en torno a la conservación de una condición (a la vez, oficio, privilegio y estatuto) otorgada y reconocida por grupos sociales más amplios" (Donzelot 1998: 51). En este contexto de verticalización de las relaciones familiares, cabe analizar de qué manera se ha ido construyendo el vínculo de la mujer con el ámbito privado del mundo doméstico, en tanto escenario que se le ha designado como propio e inherente históricamente.

En relación con lo anterior si bien la consolidación de la familia intima ocurre durante siglo XIX, Michel Perrot sostiene que la asociación naturalizante entre la mujer y lo doméstico se encuentra presente prácticamente en todas las culturas, las que a partir de diferentes estrategias y disposiciones socioculturales tienden a contribuir a fomentar una relación esencialista que opera desde una división dicotómica: la esfera masculina y femenina (Perrot 2009)
Cabe destacar además que el conjunto de atribuciones asociadas al hogar y lo doméstico están cargadas de connotaciones positivas, que tienden a instalar un imaginario bucólicoromántico, lo que se expresaráen la mayoría de los estudios referidos a estas temáticas. Sin embargo, desde una perspectiva crítica han surgido visiones que cuestionan este reduccionismo. En esta línea, la antropóloga Mary Douglas (1991) señala que la noción contemporánea de hogar, ligada al concepto de refugio o a su papel en la estabilidad de la personalidad, provienen de una construcción particular desarrollada por la cultura occidental en el siglo XIX; por tanto constituye una construcción histórica y cultural que debe ser problematizada, revelando su rol en el disciplinamiento del cuerpo y la mente, como lugar que representa la autoridad paterna y encarna divisiones de género. El hogar entendido desde esta perspectiva disciplinaria pone en duda la privacidad personal, otro de los atributos que históricamente se le han vinculado, provocando lo que Douglas denomina tiranías del hogar (Douglas 1991).

El proyecto doméstico anunciado por George Teyssot, abarcaría un arco temporal que se extiende desde el siglo XVIII hasta la década del $70^{\prime}$ del siglo XX y tendría un carácter político, económico y social, referido principalmente al control de los individuos en el espacio privado de la familia y la regulación de los hábitos de la intimidad, desde la domesticación de la vida social, incluyendo la normalización- moralización de la población basada en técnicas de control de los cuerpos, el espacio y el comportamiento (Teyssot 1988) tal como sugieren los estudios biopolíticos de Foucault (1998), Ranciere (2005) y Donzelot (1999). En este sentido, lo doméstico desde el punto de vista físico y simbólico puede entenderse como dispositivo que produce 
relaciones fundantes entre hombres y mujeres (Illich1987).

En este marco, se desplegarán formas de control social en relación a la familia, desde la primacía de la ideología familiar entendida como aquel tipo relación de parentesco que universaliza el rol de la familia nuclear basada en una estricta división sexual del trabajo, asentada en la figura de la mujer como madre y dueña de casa vinculada al mundo privado del hogar y del hombre como proveedor relacionado con el ámbito de lo público a partir del trabajo (Beechey 1985).

\section{Estado, modernización y hogar en América Latina durante la primera mitad del siglo $\mathrm{XX}$}

Cabe considerar como antecedente los aportes generados por los estudios de género en América Latina en estas temáticas. La relación entre el Estado y la vida doméstica ha sido abordada desde diferentes puntos de vista. Destacan entre otros los trabajos de Asunción Lavrin, Maria Emma Mannarelli y Donna Guy, los que constituyen importantes aportes en estas materias, en la medida que han relevado la relevancia de abordar históricamente la situación de las mujeres América Latina a lo largo del siglo XX y especialmente de ahondar en la comprensión de la importancia de la vida privada.

En este sentido, Lavrin ha analizado el papel del Estado en relación con la vida doméstica y el hogar, especialmente durante la primera mitad del siglo XX a partir de la creciente incorporación de la mujer al mundo laboral fuera del hogar. La autora señala que, en Argentina, Chile y Uruguay, la discusión por parte de las feministas estaba centrada en torno a conciliación entre trabajo y maternidad, tema que convocaba a la izquierda política y reformadores sociales liberales y que tuvo como resultado una serie de medidas de asistencia y protección social enfocadas en las mujeres, muchas de las cuales se materializaron luego de 1940 (Lavrin 2005). María Emma Mannarelli ha contribuido con el análisis de la relación entre el discurso médico y Estado en el caso peruano, destacando la relevancia de las reformas higienistas desarrolladas desde principios del siglo XX. Dichas reformas dan cuenta del intento por fortalecer una identidad femenina sustentada en la maternidad $y$ enraizada en la familia nuclear, la que tenía como referente la imagen de la "casa cerrada", por lo que apuntaban hacia la privatización del espacio familiar (Mannarelli 1999).

En el caso argentino Donna Guy ha abordado la situación de las mujeres bajo el Estado de Bienestar. Específicamente se ha enfocado en la comprensión del rol del feminismo, la filantropía las mujeres y la infancia durante la primera mitad del siglo XX (Guy 2011).

En el caso chileno estos debates no han estado ajenos y la disputa en torno a la naturalización del vínculo entre lo femenino con lo privado y lo masculino con lo público, ha sido un tema central en las transformaciones que ha experimentado la familia chilena a lo largo del siglo XX.

Un caso interesante que permite problematizar y tensionar la distinción entre lo privado- femenino y lo público masculino, corresponde a la lucha que dan las mujeres en la mina el Teniente frente a la compañía Braden Cooper Company, el programa de bienestar de la compañía se focalizó en la regulación de las relaciones entre hombre y mujeres en el campamento, desde la lógica de la ideología doméstica, que apelaba a 
transformar a los hombres solteros en hombres casados en familias nucleares bien constituidas, construyendo por ejemplo mayor cantidad de viviendas para matrimonios, lo que señala Klubock al respecto es que tanto hombres como mujeres se resisten al disciplinamiento impuesto por la compañía sobre todo en lo que respecta a la normalización de la familia nuclear. Por ejemplo, muchos mineros tienen dos mujeres y las mujeres pese a cumplir con el rol de dueñas de casa y esposas desempeñan, una importante participación política a través de la organización de ollas comunes participando activamente en los conflictos de la empresa con los trabajadores (Klubock 1995).

Por su parte, Ximena Valdés (2007) sostiene que los recientes procesos de modernización experimentados por la sociedad chilena han llevado a una transformación de la familia que más allá de sus dimensiones estructurales, biológicas o morfológicas, apelan a la readecuación de la vida privada, expresada en una mutación de sus relaciones. La familia sería considerada mayoritariamente como espacio de resguardo frente a las inminentes transformaciones sociales y en ese marco, el rol tradicional de la mujer vinculado con el universo doméstico es altamente valorado por amplios sectores sociedad chilena. Especialmente, este sería el modelo al que aspiran los sectores populares, privilegiando la permanencia de la mujer en la casa, como mecanismo a partir del cual es factible impedir el desorden moral de los hijos (Valdés 2007).

Este artículo plantea que estos discursos dan cuenta de un momento histórico que se enmarca en un amplio y complejo proceso modernización y racionalización de la acción del Estado sobre la sociedad, el que se venía gestando desde fines del siglo XIX y principios del XX. Proceso histórico desplegado a nivel latinoamericano donde es posible reconocer un conjunto de prácticas biopolíticas a partir de la relación del Estado con lo doméstico.

Si bien los trabajos que hemos mencionado anteriormente han avanzado en estas materias de manera significativa, abordado la rearticulación entre la esfera pública y privada a partir de análisis de la acción del Estado en diferentes niveles, proponemos abarcar específicamente el discurso estatal plasmado en publicaciones institucionales de época y sus efectos sobre el ámbito privado del hogar, especialmente a partir del vínculo entre la mujer y el hogar.

\section{Biopolíticas de la vida doméstica en Comuna y Hogar y Servicio Social.}

Iniciada durante la dictadura de Ibáñez del Campo " "Comuna y Hogar" estaba destinada a divulgar la labor de los municipios en sus funciones administrativas y legislativas, así como a la difusión de las actividades de las juntas de vecinos, esta revista apela a la modernización de las municipalidades y la legitimación de los alcaldes. Lo interesante es que, junto a lo anterior, se incorporan un conjunto de artículos relativos con el hogar, la mujer y la vida doméstica, en los que destaca la importancia del rol femenino en la gestión de la modernización municipal. El hogar emerge en una vinculación estrecha con la higiene así con ideas modernas en torno a la vida doméstica, asociadas al confort y el uso eficiente de los recursos. El aporte femenino

La dictadura de Carlos Ibáñez del Campo (1929-1931) inauguró un periodo de modernización, ascenso de las capas medias y el fortalecimiento del papel del Estado. Ver. http://www. memoriachilena.cl/temas/index.asp?id_ut=carlosibanezdelcam po\%281877-1960\%29 
se define, en esta perspectiva desde su gestión como dueña de casa. Esta publicación representaría, entonces los intereses específicos del municipio como entidad pública canalizando la acción estatal a nivel local ${ }^{3}$.

Servicio Social, por su parte constituye una publicación que surge el año 1927 al alero de la primera Escuela de Trabajo Social de la Junta Nacional de Beneficencia y, si bien ha sido objeto variados estudios enfocados en el rol ejercido por la trabajadora social en Chile a lo largo del siglo XX (Illanes 2007), se pretende dilucidar de qué manera el Estado desde la acción de las visitadoras sociales, elabora estrategias biopolíticas de control social destinadas al disciplinamiento de las familias, desde su acción sobre la regulación de la mujer y su rol en el escenario doméstico.

Imagen 1. Alumnas diplomadas primer curso Escuela Servicio Social 1925-1926. Fuente: Revista Servicio Social. Año $1 \mathrm{~N}^{\mathrm{a}} 11927$.

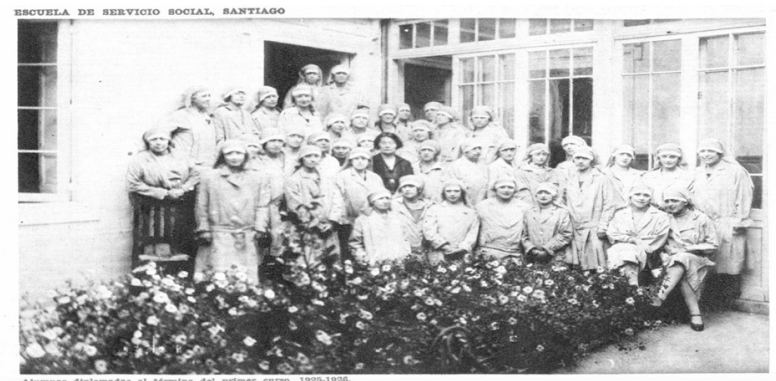

Cabe mencionar que en el caso chileno y específicamente en el de la ciudad de Santiago, la acción de las municipalidades ha desempeñado un papel importante en lo que respecta a la puesta en marcha de políticas estatales, si bien goza de autonomía respecto de la toma de decisiones, su accionar está destinado a canalizar políticas estatales a nivel local. La ley de comuna autónoma aprobada en Chile el año 1891 le otorgó atribuciones a las comunas dando paso a la formación de las municipalidades, las que se encargaran de administrar la labor y gestión de los municipios (De Ramón, 2000,).
La Junta Nacional de Beneficencia creada en 1832 como entidad semipública tuvo un rol fundamental en relación con las acciones de beneficencia relacionadas con la salud y el higienismo, en hospitales, asilos, orfanatos. Muchas estas acciones impactaron en la regulación de la vida doméstica, sobre todo las llevadas a cabo por las visitadoras sociales, que realizaban un importante trabajo de adiestramiento y disciplinamiento sobre los sectores populares a partir de las visitas domiciliarias, experiencia que quedó plasmada en esta publicación.

El rol del Estado respecto de la regulación de la vida hogareña en el periodo oscilará entre ideas enfocadas en los preceptos del higienismo que ya hemos mencionado y aquellas ligadas con la eficiencia en el manejo del presupuesto familiar, desde una mirada que se despliega a partir de una concepción biopolítica en relación con las clases sociales, esto implica un deseo de control físico y moral así como un proceso de ajuste doctrinariopedagógico de los sujetos a un determinado proyecto colectivo. Las mujeres serían por tanto sujetos de interés principal del aparato tecnológico del gobierno, desde su intento de manejo y control social expresado en la producción de familias ajustadas ética, física y moralmente con el proyecto modernizador del Estado.

Cabe destacar que las transformaciones provocadas por el proceso de industrialización impactaron sobre las familias urbanas particularmente en aquellas que migraron del campo a la ciudad (Pieper 2009) las que modificaron su estilo de vida familiar a partir de las nuevas exigencias emanadas del proceso de industrialización y el trabajo asalariado. En este escenario el Estado desempeñará un importante papel en el periodo a partir del despliegue de 
mecanismos y estrategias de intervención social sobre la vida doméstica, marco en el que estas publicaciones se insertan discursivamente.

Es necesario considerar que, durante la primera mitad del siglo XX en el caso chileno, tomará especial relevancia el rol desempeñado Gobiernos Radicales (1938-1952) y especialmente por el Frente Popular (1936-1941), impulsando medidas modernizadoras aparejadas con la preocupación por la cuestión social. Tal como ha sido señalado por otros estudios (Illanes 2007, Rosemblatt 1995) el Frente Popular jugó un papel clave en la consolidación de la familia, liderando un proceso de transformación social caracterizado por el ascenso de las clases medias y una nueva concepción del Estado en su vínculo con la sociedad como lo ha planteado María Angélica Illanes.

La labor de disciplinamiento del Estado, sin embargo, destaca por apelar a un trabajo de connotación pedagógica, es decir no opera desde el ámbito represivo, aludiendo más bien a un proceso de adiestramiento encarnado, por ejemplo, a partir de la educación de economía doméstica, tal como señala Rosemblatt, los hombres, preferirían aquellos hogares limpios y cuidados y muchas mujeres "se habrían hecho miembros de la Asociación de Dueñas de Casa a partir de 1947 para tener acceso a los alimentos baratos distribuidos por este organismo estatal, debieron asistir a charlas de economía doméstica en donde se les enseñaba a ser buenas madres y esposas" (Rosemblatt,1995:185).

\section{El rol disciplinario de la asistencia social femenina}

Por otra parte, la acción de las visitadoras sociales con respecto a su intervención en la vida familiar y el escenario doméstico, será acompañada por instituciones sociales en las que desempeñan su labor asistencial y que comienzan a tomar fuerza en el periodo. Muchas de estas instituciones dependen de la Junta de Beneficencia misma que inaugura la Escuela de Servicio Social en 1927.

En este sentido, el periodo analizado destaca por constituir una etapa en la cual las estrategias de control social y prácticas policiales sobre las familias obreras no han sido asumidas totalmente por Estado. De este modo, aún hacia fines de los años 20' el Estado desarrolla un trabajo de intervención compartido con la acción caritativa liderada sectores privados de la elite. Ejemplo de ello es El Patronato de la Infancia fundado en 1906 que viene a ser una de las principales instancias que inauguran la asistencia social en Chile, el que a su vez fue precedido por instituciones de caridad destinadas al cuidado de la infancia como el Instituto de Puericultura, la primera dedicada al cuidado de los niños de familias obreras atendido por matronas (Illanes 2007).

En 1911 junto con el Patronato de la Infancia surge la Gota de Leche la que, si bien es previa a la acción de las visitadoras sociales, será una de los escenarios centrales desde donde sobre las familias obreras.

\section{Como sostiene María Angélica Illanes}

\footnotetext{
... La nueva institución era una imitación de las Gotas de leche francesas y estaba dedicada a la primera infancia; su nombre sugería la entrega de leche a las lactantes que no pudiesen tomar del pecho materno. Ella fue el fruto de la tradicional iniciativa de la caridad. Señoras y monjas, apoyadas ahora con la nueva y comprometida injerencia de los médicos, capaces de "ver" la realidad a través de las estadísticas dedicados a comenzar la lucha contra la mortalidad infantil..." (Illanes 2007:137).
} 
Luego de la puesta en funcionamiento de la Escuela de Servicio Social, las visitadoras sociales jugarán un rol relevante en esta institución. dando cuneta del desarrollo de la medicina social en Chile. ${ }^{4}$ La Gota de Leche comienza a intervenir directamente sobre temas relacionados con la mujer como es el cuidado de los recién nacidos.

Imagen 2. Día de consulta de la Gota de Leche en Hospital de niños. Fuente: Servicio Social 1928.

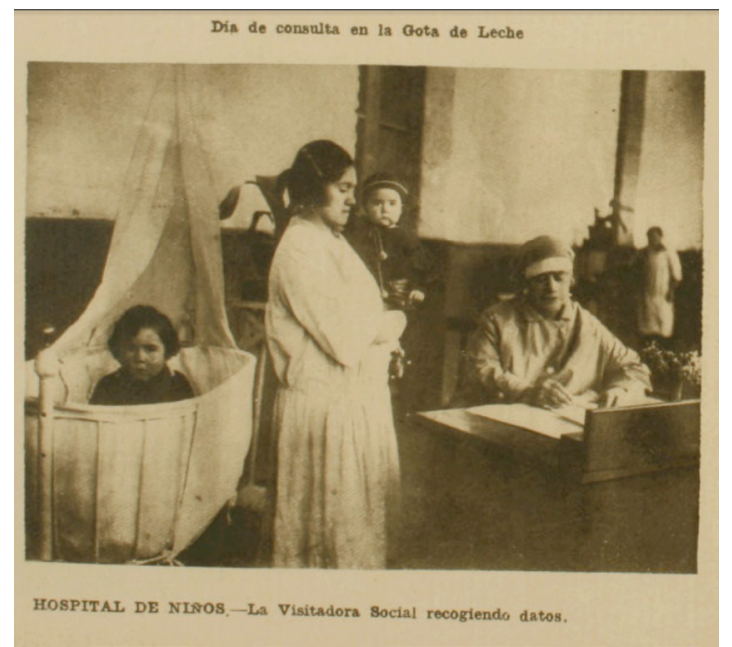

En este sentido, Servicio Social expresa un especial interés por el funcionamiento de las Gotas de Leche, lo que se expresa en un número del año 1933, en el que se describe el funcionamiento de la Gota de Leche Guzmán Montt dependiente del Patronato de la Infancia ubicada en Avenida Andes 2667 y la Gota de leche Valdés emplazada en Avenida Placer 1390, su principal foco lo constituye en la enseñanza práctica de la puericultura:

\footnotetext{
Al respecto cabe destacar que la Escuela de Servicio Social es inaugurada por el connotado médico Alejandro del Río.
}

Fomentando la alimentación natural y proporcionando la artificial científicamente preparada cuando lo determina el médico. Atención médica las (Lúes y TBC) y asistencia social para la familia mientras permanece el lactante en la Gota" (Servicio Social 1933; 62)

Junto con esta institución de asistencia médicosocial, serán de preocupación de Servicio Social otras instancias menores que prestan servicios asistenciales de socorro de los más necesitados. En este contexto, destacan las entonces denominadas ollas y los settlements. Ambas al igual que las Gota de Leche, son lideradas por hombres y mujeres de la elite y cuentan con el servicio de visitadora social.

Los settlements emergen como una suerte de centros sociales destinados cuidado de niños y jóvenes, así como al desarrollo de talleres y actividades de recreación para mujeres y hombres. Si bien no existe mucha información acerca de su implementación, al menos se sabe que uno de ellos operó en el centro de Santiago y eran recomendados por las visitadoras sociales como un espacio fundamental de ayuda a la familia.

Es por esto se ha creado centros sociales llamados Settlements que tienen como finalidad mejorar la vida material y moral y educar el medio ambiente, fuera de toda propaganda política o religiosa. Su programa comprende una acción individual, familiar y social, de cuya realización se encarga el Servicio Social (Servicio Social, 1933:119)

\section{El disciplinamiento femenino de la vida doméstica: de la casa al municipio}

Los discursos sobre la relación de lo doméstico y la mujer en "Comuna y Hogar" se sustentan principalmente en su ejercicio de la administración municipal. En una primera aproximación esta invitación, se asocia con un llamado de participación femenina en la vida pública, la que aparentemente rompe con las 
posiciones conservadoras respecto del estatus y campo de acción femenino. Sin embargo, se alude a la mujer desde su posición de dueña de casa considerando atributos que la vinculan con el cuidado de la familia y el hogar, los que le otorgarían las competencias necesariasdada su naturaleza femenina- para la gestión municipal.

En este sentido, tal como ha señalado (Pateman 2000) el Estado actúa desde una perspectiva masculinizante, que excluye a la mujer del ámbito público-masculino. Este argumento se extiende incluso en aquellos casos en donde la mujer es convocada a participar en una entidad pública comoes el municipio, que delinea cuidadosamente las labores que le competen desde su naturaleza femenina enraizada en el hogar.

\begin{abstract}
Como os he dicho, la madre está ligada por sus fibras más sensibles al problema de la ciudad, que es el de su propio hogar, y no puede desentenderse de él en ninguna de sus actividades. La dueña de casa tiene contactos diarios con los problemas del urbanismo, y si hay algo que ella no puede evitar, son sus relaciones con la Municipalidad. (...) Ninguna mujer puede vivir extraña a estos problemas diarios de la vida doméstica, que son la vida misma. Ninguna debe desinteresarse, ni mostrar indiferencia por lo que afecta tan directamente como esposa y como madre, o como simple vecina de la ciudad (Mackena, 1929: 169).
\end{abstract}

Como se desprende de la cita anterior -que corresponde a un extracto del discurso de Alberto Mackenna en 1929 al Circulo de Señoras, publicado en "Comuna y Hogar"- del cual se desprende un discurso ambiguo que por un lado convoca a la mujer a participar en la actividad pública, y por otro lado reduce lo femenino a sus competencias en la esfera doméstica. Más allá de constatar que la mujer es relegada al ámbito de lo privado -hogareño y el hombre a lo público- estatal, los límites y fronteras entre ambas esferas presentan porosidades aparentes, que en una mirada preliminar dejan entrever un proceso de modernización, que en términos efectivos da cuenta de la lógica masculina sobre la cual se ha levantado el estado moderno patriarcal (Pateman 2000).

Esta contradicción es argumentada, en un artículo posterior, que declara el quehacer municipal como un campo de acción que no constituye un trabajo político- ámbito masculino por excelencia- condición que habilita la gestión municipal como espacio apropiado para el mundo femenino. Sin embargo, desde la crítica feminista contemporánea, la vida doméstica y el hogar serían intrínsecamente ámbitos políticos, en la medida que los temas personales, que configuran el ámbito privado familiar, no pueden ser vistos como elementos ajenos al accionar público (Pateman 2000). La división patriarcal entre lo público y privado se deja entrever en estos discursos, expresándose en el conjunto de asociaciones respecto de lo femenino y lo masculino, las que corresponden a construcciones sociales históricamente situadas, que operan desde una lógica dicotómica, donde la mujer y la vida política serían incompatibles (Pateman 2000).

Es indudable que la política es incompatible con la mujer. Y ello se explica, porque su temperamento suave, tranquilo, acogedor y dulce. En esa lucha de todos los momentos está bien el hombre, que es belicoso e impulsivo por naturaleza, pero nó la mujer, a la que en el mejor de los casos - le faltan seguramente condiciones. (...) Los Municipios, de acuerdo con el espíritu que los creó y con su razón de ser y existir, nada tienen que ver con la política. El Municipio es una corporación administrativa, encargada de velar por la ciudad.(...). Y estas funciones concuerdan maravillosamente con la mentalidad y los sentimientos de la mujer, que - así como es buena madre en el hogar - puede serlo desde las altas esferas municipales. De aquí que, sin que esto signifique amenguar el buen sentido y las rectas inspiraciones de muchos hombres, la mujer está muy bien en el desempeño de las funciones edilicias (López, 1939; 7). 
Por su parte, "Servicio Social", abordará el estatus público de la figura de la dueña de casa, lo que se consagrará en la creación de la Asociación de Dueñas el año 1947. Tal como vemos en un extracto del informe publicado en esta revista por Clara Williams de Lunge, esta asociación nace como una invitación de la primera dama, Rosa Markman, esposa del presidente Gabriel González Videla, para que las mujeres participen activamente en uno de los principales objetivos del gobierno: mejorar el uso de los recursos destinados al hogar. Para extender esta agrupación se crearon agrupaciones de dueñas de casa lideradas por la esposa del alcalde, específicamente:

\footnotetext{
Se acordó encargar a los Alcaldes de la provincia de Santiago y a los Intendentes y Gobernadores del resto de la República formar grupos comunales de dueñas de casa dirigidos por la esposa del Alcalde o por la persona que éste designara. nombrado entre las socias de la Asociación, un grupo de Inspectoras Ad honorem que tienen las mismas atribuciones que un Inspector del Comisariato (Williams de Lunje 1947; 70)
}

Desde esta lógica, lo femenino deviene en una categoría definida desde connotaciones naturalizantes contribuyendo a la configuración de una suerte de ontología de lo doméstico que opera desde la inquebrantable diada mujerhogar. Dicha ontología responde a un periodo de fuertes transformaciones sociales destacando la emergencia de la mujer en la vida pública. Específicamente se espera que las dueñas de casa, cumplan un rol fiscalizador, para lo cual deberán ser formadas como inspectoras ad honorem, dedicadas a resguardar el gasto familiar. Lo interesante es además su formación estaba orientada manejo de la nutrición familiar.

Esta labor educativa va orientada de preferencia a formar Inspectoras que, compenetradas de la finalidad de la Asociación, propaguen a su vez, estos conocimientos preparando y enseñando a otras dueñas de casa, de su barrio respectivo, a trabajar en la labor de fiscalización en el comercio; y, dentro e sus hogares, a comprar y utilizar en la mejor forma los alimentos y artículos de consumo (Williams de Lunje 1947;70).

En este sentido, estas publicaciones juegan un rol relevante en el plano discursivo -ideológico desde la perspectiva biopolítica asociada con el gobierno de la esfera doméstica y de regulación del campo de acción de hombres y mujeres al interior del hogar, contribuyendo con la consolidación de un modelo familiar, ajustado al modelo de sociedad que emerge con el proceso de modernización. La asociación de dueñas de casa en esta línea se expresa como una extensión del rol femenino de disciplinamiento en el ámbito del hogar, hacia el barrio y la ciudad, como ámbitos de lo público, en el que se inserta la acción femenina.

\section{Del saber médico a la higiene y orden moral del hogar}

Dentro del conjunto de secciones y artículos publicados en "Servicio Social desde fines de la década de 1920, potencian la imagen de familias basadas en el orden físico y moral, compatible con el proyecto modernizador del Estado. En este proceso será fundamental el rol ejercido por las visitadoras sociales, quienes pasan de ejercer su rol en el contexto de los hospitales a las visitas domiciliarias (Illanes, 2006). A partir de la perspectiva disciplinaria basada en los preceptos de la biopolítica de Foucault (1998) y policial de Donzelot (1998), su labor tiene como objetivo contribuir con el orden moral de la familia como mecanismo de control social.

La figura de la madre en el hogar es altamente valorada, pese a que al igual que en "Comuna y Hogar" existen atisbos de una concepción modernizadoradelafigurafemenina, porejemplo, 
a partir de su inserción en el mundo laboral. En efecto, si bien se señala que la presencia de la madre en la casa es irremplazable, se propone la opción del trabajo de medio tiempo, el que sería compatible con sus actividades como dueña de casa y madre, junto con lo que plantea una mayor participación del hombre en las labores del hogar. Como podemos apreciar en el siguiente extracto, pareciera existir un intento por conciliar los roles de género, percibiendo un intento por equilibrar en alguna medida las labores al interior del hogar. De alguna manera este argumento devela y da cuenta del peso que implicaba el trabajo doméstico en la medida que se sugiere que la mujer que trabaja medio tiempo requiere de un apoyo familiar extra para las labores diarias de mantención del hogar, pero a la vez expresa una modernización limitada que aboga por la compatibilización de las labores dentro y fuera del hogar. Es decir, la presencia de la figura femenina al interior de la casa es clave, para la consolidación del modelo familiar al que apela el Estado moderno de los años 30 el que descansa la figura femenina de dueña de casa, madre y esposa.

La afirmación de que la presencia de la madre en el hogar, de que la actividad desplegada por ella en sus diversos dominios representa un valor financiero superior a lo que ella podría ganar, debe ser tomada en consideración, a pesar de que las comparaciones matemáticas no siempre la favorecen. ¿Por qué no preconizar un sistema intermedio medio día de trabajo, de manera que, aportando a la familia una ayuda, sin la cual no podría pasarse, permite a la madre asumir, completa o parcialmente las diversas tareas de la casa? (Salas 1935)

Por otra parte, un punto interesante de resaltar con respecto a Servicio Social son los temas que coloca como su centro de interés. Además de identificar una serie de problemáticas ligadas a la familia de la primera mitad del siglo XX, como el de la madre soltera, la delincuencia juvenil o el alcoholismo, hemos podido establecer un conjunto de tópicos de interés para las visitadoras sociales, todos vinculados con los efectos del proceso de urbanización y de industrialización del periodo. Específicamente destaca la preocupación por la familia obrera; ya sea la del trabajador de ferrocarriles del Estado del obrero del salitre.

\begin{abstract}
La mayoría de los obreros que ganan entre $\$ 300$ y $\$ 500$, viven en pésimas condiciones higiénicas. Ocupan una pieza miserable de un conventillo o casa particular cuyo canon fluctúa entre los $\$ 30$ y los $\$ 60$ : Algunos pagan $\$ 15$ por chozas de tablas. En general estas piezas son insalubres, carecen de sol y de ventilación suficientes; tienen el piso de tierra, a más de ser sumamente pequeñas. Esta habitación estrecha, incómoda y desagradable aleja al hombre del hogar y lo lleva al cabaret, al alcohol, la cantina, etc. Existe una relación estrecha entre las condiciones defectuosas del hogar y el alcoholismo, el abandono de aquel, la mala salud, etc. Nada de práctico no de definitivo se puede hacer en materia de higiene y de progreso social, mientras la cuestión de alojamiento no esté resuelta para todos (Camacho 1934; 297)
\end{abstract}

Como se desprende de la cita, que corresponde a un artículo de una visitadora sobre el rol de Servicio Social en Ferrocarriles del Estado durante la década del 30- la preocupación por la situación de la familia obrera se articula en torno a las condiciones higiénicas de su habitación, junto a los hábitos desarrollados en torno a la vida familiar. El hogar es descrito como el elemento que gatilla o potencia comportamientos inadecuados como el alcoholismo y abandono del hogar por parte del padre de familia. En este sentido, una de sus preocupaciones, será las condiciones de las viviendas obreras

En esta misma línea encontramos en "Comuna y Hogar" artículos referidos a la necesidad de 
inculcar en las familias obreras las nociones de orden y cuidado del hogar en todos sus aspectos. Orden, cuidado y limpieza de la casa que depende de la mujer y del que a su vez dependería el bienestar integral de la familia y sobre todo el necesario y merecido descanso del padre de familia, de quien depende el éxito de la familia nuclear.

Generalmente la "casa" - home- es el sitio en que el cabeza de familia come y duerme, y ello se debe casi exclusivamente a que la mujer chilena no tiene una fuerte educación en lo referente a economía doméstica. (...). La mayor parte de los defectos de nuestra raza tienen su cuna en la desorganización del hogar, en la falta de armonía de sus factores constitutivos. (...). (Walton 1931; 71).

En este sentido, es de interés de ambas publicaciones dar cuenta de las consecuencias que el proceso de urbanización produjo sobre las familias más desfavorecidas en términos de su integración al relato del progreso. Es aquí donde toma mayor fuerza la mirada biopolítica (Foucault, 1998), entendida como control, sobre el cuerpo total de las familias, de ahí que las visitadoras sociales inicien su labor en los hospitales colaborando estrechamente con las preocupaciones médicas de la época en cuanto a salud e higiene y luego como hemos adelantado se insertarán en el centro de la vida doméstica, interviniendo directamente en el hogar desde este conocimiento especializado a partir de la aplicación de la encuesta domiciliaria, instrumento que permitía recabar información fundamental para ejercicio del disciplinamiento social de la familias obreras.

En este sentido, el proyecto doméstico (Teyssot 2005) comprende el saneamiento de las malas prácticas de las familias obreras como el alcoholismo y las condiciones de higiene, las que únicamente pueden resolverse en la medida que se solucione el problema de la habitación. Se parte del entendido de que existe una
Imagen 3. Habitación de una familia indigente antes de la asistencia de la visitadora social. Fuente: Revista Servicio Social 1928.

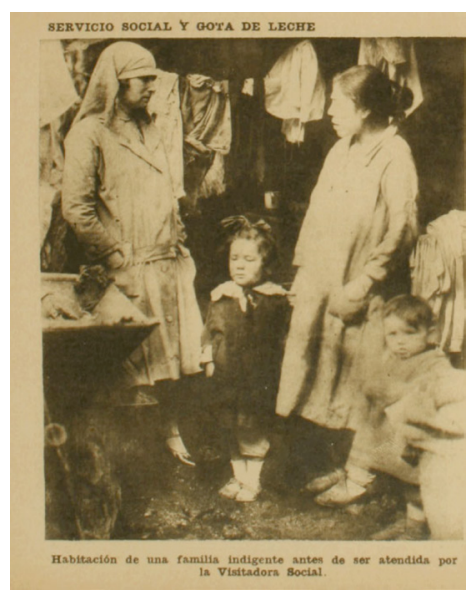

relación directa entre la solución del tema del alojamiento con las problemáticas de atañen a las familias populares, tal como se plantea en "Servicio Social" del año 1934.

Las políticas sociales destinadas a la solución de la vivienda obrera que se implementan durante la primera mitad del siglo XX fueron llevadas a cabo considerando estas problemáticas, muchas de las cuales fueron detectadas por la labor disciplinaria-policial de las visitadoras sociales, quienes llevaron a cabo intensas jornadas de trabajo en terreno, experiencias que luego eran divulgadas a través de artículos o monografías en "Servicio Social". El papel de las visitadoras sociales desde el punto de vista de su labor asistencialista destinada a la civilización del cuerpo social desde un conjunto de estrategias y técnicas (Foucault 1998; Donzelot 1998)

Por otra parte, dentro del discurso disciplinario que promulga el Estado para la familia popular 
obrera, sobresale la incorporación de preceptos modernos como el ahorro y el control eficiente de los gastos domésticos. Acciones que se articulan al ímpetu modernizador-racionalizador del estado en su concepción de la vida doméstica y en especial del rol que debe desempeñar la mujer en la economía del hogar.

\begin{abstract}
La reducción de los gastos en la mantención de un hogar, es un problema del más alto interés, cuya solución debe encarar todo jefe de familia sin perjudicar el bienestar de ella. Un rol importantísimo debe desempeñar la dueña de casa, con cuya cooperación pueden llegar a conseguirse grandes ventajas en el mejoramiento de las condiciones económicas del hogar (Parada 1930: 115).
\end{abstract}

Este manejo eficiente de los gastos al interior del hogar -que como adelantamos- llevó a la incorporación de la mujer al ámbito de la gestión municipal se relaciona con el impacto de la influencia extranjera en relación con la noción de lo doméstico y lo femenino.

\footnotetext{
......Sus hogares, por lo tanto, deben contar con todos aquellos elementos de confort, de limpieza, de luz, y alegría. Destinados a proporcionárselos" generalmente la "casa" - home- es el sitio en que el cabeza de familia come y duerme, y ello se debe casi exclusivamente a que la mujer chilena no tiene una fuerte educación en lo referente a economía (Walton 1931: 171)
}

Al respecto destaca la incorporación del home anglosajón en referencia a la consolidación del imaginario de familia nuclear que debe ser incorporado en las familias chilenas desde la labor pedagógica que desempeña la economía doméstica, tal como se destaca en "Comuna y Hogar" en relación con el hogar como lugar de descanso del padre de familia.

\section{Conclusiones}

Si bien Chile a lo largo del siglo XX ha experimentado importantes procesos de modernización, no ha logrado consolidar una imagen moderna de lo femenino. En este sentido, la puesta en marcha de la modernización durante la primera mitad del siglo XX se basó en una visión de la familia como cuerpo social disciplinado anclado en una estricta división de los roles de género donde la naturalización de la relación mujer - hogar será central. Argumento que descansa en lo que Antonieta Vera denomina, como el discurso retórico de la modernidad acerca de "la superioridad moral de la mujer", retórica específicamente moderna en la medida que se inspira en un argumento sociológico y científico clave de la época "la naturaleza diferente y complementaria de los sexos" (Vera, 2012).

En tal sentido, "Comuna y Hogar" y "Servicio Social" constituyen publicaciones que nos permiten develar, en alguna medida, la perspectiva tanto del Estado como de la sociedad respecto del vínculo de la mujer con el hogar. Desde este punto de vista en ambas publicaciones es posible identificar un llamado a la mujer como contenedora del hogar desde una mirada esencialista acerca de sus atributos. Por otro, ambas develan la necesidad de intervención estatal, ya sea desde la acción municipal como desde las diferentes instituciones de asistencia social presentes en el periodo, ejemplo de ello es labor desempeñada por las visitadoras sociales.

En esta perspectiva a modo de síntesis, es interesante como los argumentos de Teyssot en relación con el proyecto doméstico (2005) y Douglas (1998) en relación con las "tiranías del hogar "se manifiestan en el espíritu que alimenta estas publicaciones, el que opera desde una lógica destinada a la producción de una mayor cohesión social de la familia obrera, 
acorde con los objetivos propios del Estado moderno patriarcal que describe notablemente Pateman. De allí la necesidad de un proceso de adiestramiento pedagógico, que opera desde formas de control disciplinario expresadas discursivamente en estas publicaciones los que dejan entrever una normalización de las prácticas cotidianas al interior del hogar desde una estrategia biopolítica que conjuga formas de disciplinamiento ético -moral de los cuerpos que subyacen a las políticas higienistas que proliferan a lo largo de la primera mitad del siglo XX. Del mismo modo la lógica policial de las familias que propone Donzelot (1998) cobra sentido en la medida que estos discursos, apuntan a generar mecanismos que fomenten una clara distinción de los roles de cada uno de los miembros de la familia.

A modo de reflexión final cabe mencionar que uno de los temas claves que pueden ser desarrollados más adelante respecto de la relación entre el Estado, el hogar y la mujer corresponde al rol de las políticas de vivienda.

Para cerrar, cabe destacar que la relación entre Estado y hogar en América Latina durante la primera mitad del siglo XX se enmarca en un contexto de profundas transformaciones sociales, que tal como hemos expuesto tienden hacia una racionalización modernizadora de la figura de la familia bajo la consolidación del Estado moderno.

En el caso de Chile destaca el impacto de la incorporación de un conjunto de nociones vinculadas con la vida doméstica que se introducen a través de la labor desempeñada por las visitadoras sociales las que inician su labor asistencial en los hospitales para luego introducirla personalmente en las viviendas de las familias obreras. Será desde el trabajo desarrollado durante esas visitas, que divulgan en la revista "Servicio Social", el escenario desde el cual se objetiva la ideología familiar que esta difunde.

Por su parte, "Comuna y hogar" da cuenta de las percepciones e imaginarios que circulan en torno a la mujer y el hogar en el periodo desde el punto de vista de los municipios y el modo en que, si bien se convoca a la labor de la mujer a nivel municipal, esta se restringe a su condición ontológica de dueña de casa y a un conjunto de atributos que se definen como naturalmente femeninos. De este modo, es una invitación que descansa en la dicotomía propia de del Estado moderno patriarcal entre la esfera privada ligada a lo femenino y al hogar y la pública relacionada con lo masculino.

\section{Bibliografía}

Álvarez, P. 2011. Mecánica doméstica. Publicidad, modernización de la mujer y tecnologías para el hogar 1945-1970. Santiago: Ediciones UC.

Ariés, P. y Duby, G. (ed) 2001. Historia de la vida Privada 4. De la revolución Francesa a la Primera Guerra Mundial. Argentina: Paidos.

Beechey, V. 1985. "Familial Ideology". Subjetivity and social relations. Editado por Veronica Beechey y James Donald.
Philadelphia: Open University. 98-120.

Brown, W. 1995. States of Injury: Power and Freedom in Late Modernity, Princeton: University Press.

Camacho, E. 1934. "El servicio social en los ferrocarriles del Estado". Servicio Social. Año VIII (3): 278 -309.

Cereceda, Berta 1937. "Servicio Social Rural". Servicio Social. Año XI (3): 186-191.

Das, V. y Poole, D. 2008. "El Estado y sus márgenes. 
Etnografías comparadas". Cuadernos de Antropología Social. (27): $19-55$

Delagrange 1935. "El Servicio Social y la familia como unidad económica, espiritual y moral”. Servicio Social Año IX (2):90-93.

De Ramón, A. 2000. Santiago de Chile. Santiago: Editorial Sudamericana. textos.

Donzelot, J. 1998. La policía de las familias. Santiago: Pre-

Douglas, M.1991. "The home a kind of space". Social Research 58 (1): 227-295.

Foucault, M. 1998. Vigilar y Castigar: el nacimiento de la prisión. México: Siglo XXI. .2008 [1977] .Historia de la sexualidad. Vol 1. La voluntad de saber., Buenos Aires: Siglo XXI.

1999 Hermenéutica, ética y estética. México: Fondo de

Cultura Económica Gedisa.

Geertz, C. 2003. La interpretación de las culturas. Barcelona:

Guy, D. 2011. Las Mujeres y la construcción del Estado de Bienestar. Caridad y creación de derechos en Argentina. Prometeo. Argentina.

Illanes, M. 2007. Cuerpo y sangre de la política. La construcción histórica de las Visitadoras Sociales (1887-1940). Lom. Santiago.

Illich, I. 1987. "El género del espacio. El hogar vernáculo". Casa, cuerpos y sueños. A\&V Monografías de Arquitectura y Vivienda, (12): 28-31.

Klubock, T. 1995. "Hombres y mujeres en el teniente La Construcción de género y clase en la minería chilena del cobre, 1904-1951". El Estado Disciplina y desacato: construcción de identidad en Chile siglos XIX y XX. Editado por Godoy Lorena et al. Santiago: Sur-Cedem.223-253.

Lavrin, A. 2005. Mujeres, feminismo y cambio social en Argentina, Chile y Uruguay: Centro de investigaciones Diego Barros Arana.

López, R. 1939. "La mujer en las funciones edilicias". Boletín Municipal de la República. Año VIII. Mayo. (93) :7-8.

Mannarelli, M. 1999 Limpias y modernas. Género, higiene y cultura en la Lima del novecientos. Lima: Ediciones Flora Tristán.

Mackenna, A. 1929 "Los problemas del urbanismo y la mujer.

Conferencia dictada en el Club de señoras, por don Alberto Mackenna". Comuna y Hogar. Noviembre 1929. Santiago de Chile. Año I N ${ }^{\circ} 5$ (1)169-170.

Pateman, C. 2000. "El Estado de Bienestar Patriarcal". Contextos Santiago: Programas de Estudios de Género. Pontificia Universidad Católica de Chile. Año $2 \mathrm{~N}^{\circ} 5$.

Parada, E. 1930. "La economía del hogar." Comuna y Hogar. Año II 15 (3)115.

Perrot, M. 2001. "Formas de habitación". Historia de la vida Privada 4. De la revolución Francesa a la Primera Guerra Mundial.
Dirigido por Philippe Ariés y Georges Duby. Buenos Aires: Taurus. 301-316.

2009. Historias de las alcobas. México: Fondo de Cultura Económica.

Pedraza, Z. 2004."El régimen biopolítico en América Latina. Cuerpo y pensamiento social". Revista IberomericanaAmeririkanisches Institut. 4(15): 7-19

Pérez F. y Godoy C. 2009. "Territorios imaginarios de lo doméstico. Vida cotidiana en las revistas femeninas 1930-1950: el caso de Margarita". Revista Chilena de Antropología Visual (13): 104-128

Pieper, J. 2009. The politics of Motherhood. Maternity and women's rights in twentieth -century Chile. Pittsburgh.:University PittsburghPress.

Ranciere, J. 2005. El Desacuerdo. Política y filosofía. Ediciones. Buenos Aires: Nueva Visión.

Rosemblant, K. 1995. "Por un hogar bien constituido". El Estado Disciplina y desacato: construcción de identidad en Chile siglos XIX y XX. Editado por Godoy Lorena et.al. Santiago: SurCedem.181-222.

Servicio Social 1933. Año VII (1):119

Salas, M. 1935. "La educación familiar. Primera conferencia del Curso sobre Educación Familiar, organizado por la Universidad de Chile". Servicio Social Año IX (2)::69-75.

Taylor, C. 2004 Modern Social Imaginaries. Duke: Duke University.

Teyssot, G. 2005. "A topology of thresholds". Home Cultures. Vol.2. (1): 89-116.

.1988."Lo social contra lo doméstico. La cultura de la casa en los últimos dos siglos. A\&V Monografías de Arquitectura y Vivienda. "El Espacio Privado". (14) 8-11.

Valdés, X. 2007. La vida en común. Familia y vida privada en Chile y el medio rural en la segunda mitad del siglo XX. Santiago: Lom.

Valdés, X, Caro P., Peña, D. 2001. Género, familia y matrimonio: La visión de las visitadoras sociales católicas entre 1930-1950. Revista de la Academia. Universidad Academia de Humanismo Cristiano, Santiago .(6): 177-206.

Vera, A. 2012 "La superioridad moral de la mujer': El Estado Higienista y 'la buena femineidad nacional' (Chile, 1920-1930)". Colonialidad/Decolonialidad del Poder/Saber. Miradas desde el Sur. Valdivia: Ediciones Universidad Austral de Chile. 211.222.

Walton, J. 1931. "El Hogar Chileno Actual. Sugerencias. Lo que deber ser.-Preceptos científicos. - El reposo cotidiano Sugerencias". Comuna y Hogar. Año II. (4):171-172.

Williams, de Lunje C. 1947 "Asociación Nacional de dueñas de casa”. Servicio Social.Año XXI (3) :70-72.

Wunenburger, J. 2008. Antropología del imaginario. Buenos Aires: Ediciones del Sol. 